\title{
An Approach for Real Power Scheduling to Improve System Stability Margins under Normal and Network Contingencies
}

\author{
K. Visakha D. Thukaram * Lawrence Jenkins
}

Department of Electrical Engineering, Indian Institute of Science, Bangalore 560 012, India.

\begin{abstract}
In the present day power system planning and operation, considerable interest is being shown in system security and stability analysis. Pattern of load sharing / generation scheduling that results in heavy flows tend to incur greater losses, threaten stability, security and ultimately making certain generation patterns undesirable. Generation schedules mainly based on economic criteria may lead to lower reserve margins and therefore diminished reliability is a serious concern for the systems. With increased loading of existing power transmission systems, the problem of voltage stability and voltage collapse has also become a major concern in power system planning and operation. While the voltage stability is more dependent on the reactive power sources/voltage profile in the system, it is also a function of real power flows. In this paper, network sensitivity between load voltages and source voltages to compute voltage stability index (L), is used as the basis to evaluate desirable load sharing for improving stability margins. The proposed method has been tested on typical sample systems and also on a practical 24-bus equivalent power system, and results are presented to illustrate the proposed approach.
\end{abstract}

Keywords: planning and operation, system security, stability analysis.

\section{Introduction}

The present day power systems have evolved as large interconnected power grids to take advantages of integrated operation both technical and economical. Earlier, the individual power systems developed as self sufficient islands to match its generation to its load with system-wide planning for reserve margins, expected load growth, available generation sites and adequate transmission and reactive power capabilities. Interconnection of these island systems has great advantages to each individual system during normal operation and also during emergency conditions.

The goal of the Interconnected power grid operator is to achieve the best possible security for the network with available facilities. This requires tools for assessing the vulnerability of the grid to possible contingencies, implementing protection and controls that are responsible to the prevailing system conditions, and minimizing the likelihood of blackouts resulting from various forms of instabilities [1].

* Corresponding Author. Tel.: +91-80-3942362;Fax: +91-80-3600444. E-mail address: dtram@ee.iisc.ernet.in (D. Thukaram)
The ability to maintain voltage stability in an interconnected power grid has become a growing concern in present day stressed power systems. The monitoring and analysis of power system security has also become an integral part of modern energy management systems.

In this paper, network sensitivity between load voltages and source voltages to compute voltage stability index (L) is used as the basis to develop an approach for load sharing/generation scheduling for improving stability margins. The proposed approach gives the most desirable generation scheduling for a given network under normal and network contingency condition for improving voltage stability in addition to improving the system angular stability.

\section{Voltage Stability Index (L-Index)}

Consider a system where $\mathrm{n}$ is the total number of buses with $1,2 \ldots \mathrm{g}, \mathrm{g}$ number of generator buses, and $\mathrm{g}+1 \ldots \mathrm{n}$, remaining ( $\mathrm{n}-\mathrm{g}$ ) buses. For a given system operating condition, using the load flow (state estimation) results, the voltage stability L-index is computed as [2],

$$
\mathrm{L}_{\mathrm{j}}=\left|1-\sum_{i=1}^{g} F_{j i} \frac{V_{i}}{V_{j}}\right|
$$


Where $\mathrm{j}=\mathrm{g}+1 \ldots \mathrm{n}$ and all the terms within the sigma on the RHS of equation (1) are complex quantities. The values of

$\boldsymbol{F}_{j i}$ are obtained from the network $\boldsymbol{Y}$-bus matrix. For a given operating condition

$$
\left[\begin{array}{c}
I_{G} \\
I_{L}
\end{array}\right]=\left[\begin{array}{ll}
Y_{G G} & Y_{G L} \\
Y_{L G} & Y_{L L}
\end{array}\right]\left[\begin{array}{c}
V_{G} \\
V_{L}
\end{array}\right]
$$

Where $\boldsymbol{I}_{\boldsymbol{G}}, \boldsymbol{I}_{\boldsymbol{L}}$ and $\boldsymbol{V}_{\boldsymbol{G}}, \boldsymbol{V}_{\boldsymbol{L}}$ represent complex current and voltage vectors at the generator nodes and load nodes.

$\left[\boldsymbol{I}_{\boldsymbol{G}}\right]=\left[I_{1}, \ldots . I_{n}\right]^{t}$ Injected currents of generator buses

$\left[\boldsymbol{I}_{\boldsymbol{L}}\right]=\left[I_{g+1}, \ldots . . I_{n}\right]^{t}$ Injected currents of load buses

$\left[\boldsymbol{V}_{\boldsymbol{G}}\right]=\left[V_{1}, \ldots . V_{g}\right]^{t}$ Complex generator bus voltages

$\left[\boldsymbol{V}_{\boldsymbol{L}}\right]=\left[V_{g+1}, \ldots . V_{n}\right]^{t}$ Complex load bus voltages

$\left[\boldsymbol{Y}_{G G}\right],\left[\boldsymbol{Y}_{\boldsymbol{G L}}\right],\left[\boldsymbol{Y}_{\boldsymbol{L} L}\right]$ and $\left[\boldsymbol{Y}_{\boldsymbol{L G}}\right]$ are corresponding partitioned portions of network $\boldsymbol{Y}$-bus matrix. Rearranging the above equation (2) we get,

$$
\left[\begin{array}{c}
V_{L} \\
I_{G}
\end{array}\right]=\left[\begin{array}{ll}
Z_{L L} & F_{L G} \\
K_{G L} & Y_{G G}
\end{array}\right]\left[\begin{array}{c}
I_{L} \\
V_{G}
\end{array}\right]
$$

Where $\left[\boldsymbol{F}_{\boldsymbol{L G}}\right]=-\left[\boldsymbol{Y}_{\boldsymbol{L} \boldsymbol{L}}\right]^{-1}\left[\boldsymbol{Y}_{\boldsymbol{L} \boldsymbol{G}}\right] \cdot F_{j i}$ are the complex elements of $\left[\boldsymbol{F}_{\boldsymbol{L G}}\right]$ matrix. This matrix gives the relation between load bus voltages and source bus voltages, which is used as basis for the desirable best load sharing/generation scheduling.

It can be shown that the stability limit is reached for $\mathrm{L}_{\mathrm{j}}=1$, when two conditions are met [2]. The first requires that all generator voltages remain unchanged, amplitude and phase wise. The second calls for nodal currents, which respond

directly to the current $I_{j}$ and are indirectly proportional to

the voltage $V_{j}$ at the node $\mathrm{j}$ under consideration. The stability margin in this case is obtained as the distance of $\mathrm{L}$ from a unit value i.e., (1-L).

While the different methods give a general picture of the proximity of the system voltage collapse, the L- index gives a scalar number to each load bus. Among the various indices for voltage stability and voltage collapse prediction, the Lindex gives fairly consistent results. The advantage of this method lies in the simplicity of the numerical calculation and expressiveness of the results. The $\mathrm{L}$ - indices for given load conditions are computed for all load buses and the maximum of the $\mathrm{L}$ - indices gives the proximity of the system to voltage collapse. An L-index value away from
1 (unity) and close to 0 (zero) indicates an improved voltage stability margin $[3,4,5,6]$.

\section{Approach for Load Sharing/Generation Scheduling}

This paper concentrates on real power scheduling for achieving improved margin of stability. The L- index is used as the basis for evaluating the most suitable real-power generation scheduling.

The L-index is function of $\boldsymbol{F}_{j i}$ elements derived from the transmission network parameters and generator/load bus complex voltages (voltage magnitudes and angles). Considering an unloaded network with nominal voltage profile, it can be seen that the L-indices for the load buses are close to 0 (zero). For a given load distribution in the system, we can have many possible combinations of generation schedules. Reactive power controls such as, generator excitations, transformer taps and switchable VAR compensators can change the reactive power flows in the network and voltage profile (voltage magnitudes) and have influence on the voltage stability index. Different possible combinations of real power generation schedules to meet a given load demand give different real power flows in the network and voltage angles which also influence the voltage stability indices. The best load sharing is obtained by using the relative proportions of generation, which are evaluated,

from the $\boldsymbol{F}_{L G}$ matrix.

\section{Evaluation of Relative Proportions of Generation (RPG)}

To illustrate the proposed method of load sharing/generation scheduling the following five-bus sample radial system-1 shown in Fig. 1 is considered.

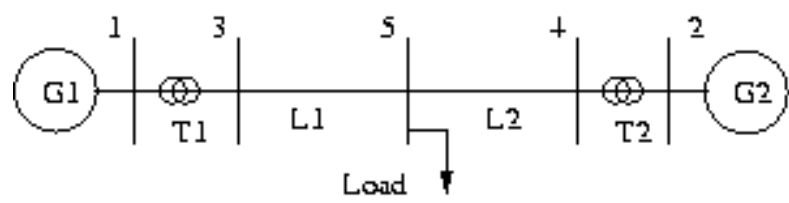

Fig. 1. Sample Radial System -1

\subsection{Case 1: Equal Line Lengths}

In this case it is assumed that the lines L1 and L2 are of $220 \mathrm{kV}$ lines of equal length of $200 \mathrm{kms}$ each. The generators considered are two units of 250 MVA with step up transformers of $250 \mathrm{MVA}$ each at both buses 1 and 2 .The $220 \mathrm{kV}$ line parameters in p.u. Per $100 \mathrm{kms}$ are $\mathrm{r}=0.0166, \mathrm{x}=0.0826$ and $\mathrm{b} / 2=0.0694$. The generator $\mathrm{X}_{\mathrm{d}}$ is

considered 0.2 p.u. on its own base. The $\left[\boldsymbol{F}_{\boldsymbol{L} \boldsymbol{G}}\right]$ matrix corresponding to the load/generator bus for the network is given by 


$$
\left[\boldsymbol{F}_{L G}\right]=\left[\begin{array}{cc}
.9516-0.0072 i & .0540+0.0069 i \\
.0540+0.0069 i & .9516-0.0072 i \\
.5146-0.0026 i & .5146-0.0026 i
\end{array}\right]
$$

\subsection{Case 2: Unequal Line Lengths}

In this case the lines L1, L2 are considered of $220 \mathrm{kV}$ of unequal lengths of $100 \mathrm{kms}$ and $300 \mathrm{kms}$ respectively with

the same generating units as in case 1. The $\boldsymbol{F}_{L G}$ matrix for this system is given by,

$$
\left[\boldsymbol{F}_{L G}\right]=\left[\begin{array}{ll}
.9519-0.0073 i & .0537+0.0070 i \\
.0537+0.0070 i & .9518-0.0072 i \\
.7400-0.0064 i & .2831+0.0025 i
\end{array}\right]
$$

The elements of $\left[\boldsymbol{F}_{\boldsymbol{L G}}\right]$ matrix are complex and its columns correspond to the generator bus numbers 1,2 and rows correspond to the load bus numbers 3,4 and 5 . It can be observed that the sums of the each row elements of the

$\left[\boldsymbol{F}_{\boldsymbol{L G}}\right]$ matrix are close to $(1.0,0.0)$. For an unloaded system with generator /load buses voltages $1.0 \angle 0$, the Lindices for load buses are close to 0 (zero), indicating that the system has maximum stability margin. For a given network as the load/generation increases the voltage magnitude and angles change and for near maximum power transfer condition the voltage stability index $\mathrm{Lj}$ values for load buses tend to close 1(unity), indicating that the system is close to voltage collapse.

\subsection{Relative Proportions of Generation (RPG) for the Sample System -1}

The relative proportions of generation to meet each load demand for the given network are obtained by taking the absolute values of the elements of $\left[\boldsymbol{F}_{\boldsymbol{L} \boldsymbol{G}}\right]$ matrix. The Relative Proportions of Generation (RPG) for the systems above case 1 and case 2 are given in Table 1 .

Table 1

Relative Proportions of Generation

\begin{tabular}{ccccc}
\hline Load Bus No. & \multicolumn{3}{c}{ Relative Proportions of Generation (RPG) } \\
\cline { 2 - 5 } & \multicolumn{3}{c}{ Case1 } & \multicolumn{2}{c}{ Case2 } \\
\hline & G1 & G2 & G1 & G2 \\
\cline { 2 - 5 } 3 & .9516 & .0544 & .9519 & .0542 \\
4 & .0544 & .9516 & .0542 & .9518 \\
5 & .5146 & .5146 & .7400 & .2831 \\
\hline
\end{tabular}

The relative proportions of generation (RPG) values are used as the basis for the best load sharing, which can also be said as optimum load sharing, as far as the system stability performance is concerned. If the generators share the load according to these relative proportions it improves the angular stability of the systems in addition to improving voltage stability.

In case 1 , since the load bus 5 is at equal distance from both the generators, the corresponding elements of $\left[\boldsymbol{F}_{\boldsymbol{L G}}\right]$ matrix magnitudes with respect to generators 1 and 2 are same i.e., 0.5146 and 0.5146 as given in Table 1. These values, which are also called as relative proportions of generation, are used for load sharing/generation scheduling.

For example, if load at bus 5 is $100 \mathrm{MW}$, then $51.46 \mathrm{MW}$ of load should be shared by generator 2 and partial remaining load (including losses) should be shared by generator 1.In case 2, similarly, if the load at bus 5 is $100 \mathrm{MW}$, then 28.31MW of load should be shared by generator 2 and partial remaining load (including losses) should be shared by generator 1. It means the load sharing/generation scheduling according to the relative proportions of generation improve stability margins with respect to voltage profile and angles.

From the above studies considered, also by intuition, we can say that, in case1, maximum load can be met by equal sharing of the load by each generator buses situated at equal distance from the load node. In case 2, the desirable load sharing has to be approximately in proportion of 0.25 and 0.75 from generators 1 and 2 respectively. Power flow analysis is carried out for the system and in case 1 and it is found that the system reaches unstable condition at a load of $325 \mathrm{MW}, 142 \mathrm{MVAR}$ (load power factor is assumed 0.9). The summary of power flow results is given in Table 2, 3 and 4 . The generator terminal voltages are $1 \angle 0^{\circ}, 1 \angle-0.5^{\circ}$ and their internal angles behind $\mathrm{X}_{\mathrm{d}}$, are $1.777 \angle 7.576^{\circ}$, $1.176 \angle 6.93^{\circ}$ giving separation of generators by a minimum angle $0.646^{\circ}$, when the load sharing is according to the relative proportions of generation. Any other combinations of generation scheduling leads lower maximum power transfer condition and also lower margin of angular stability as shown in Tables 3 and 4. Table 3 shows the variation of voltage profile (V) in pu, voltage stability index (L) and bus angles $(\delta)$, in degrees, for the sample radial system 1 .

Table 2

\begin{tabular}{|c|c|c|c|}
\hline \multicolumn{2}{|l|}{ Case 1} & Without RPG & With RPG \\
\hline \multicolumn{2}{|c|}{ Maximum Load (MW) } & 325 & 325 \\
\hline \multicolumn{2}{|c|}{ \%Power Loss } & 16.0 & 15.4 \\
\hline \multicolumn{2}{|c|}{ Power Loss (MW) } & 60.29 & 57.74 \\
\hline \multirow{2}{*}{$\begin{array}{l}\text { Generation } \\
\text { (MW) }\end{array}$} & G1 & 217 & 194 \\
\hline & $\mathrm{G} 2$ & 170 & 190 \\
\hline \multicolumn{4}{|l|}{ Case 2} \\
\hline \multicolumn{2}{|c|}{ Maximum Load (MW) } & 370 & 370 \\
\hline \multicolumn{2}{|c|}{$\%$ Power Loss } & 19.4 & 9.9 \\
\hline \multicolumn{2}{|c|}{ Power Loss (MW) } & 85.85 & 40.4 \\
\hline Generation & G1 & 229 & 305 \\
\hline (MW) & $\mathrm{G} 2$ & 230 & 105 \\
\hline
\end{tabular}

System Grid Totals 
Table 3

System Profiles

\begin{tabular}{|c|c|c|c|c|c|c|}
\hline \multicolumn{7}{|c|}{ Case 1} \\
\hline \multirow{2}{*}{$\begin{array}{l}\text { Bus } \\
\text { No. }\end{array}$} & \multicolumn{3}{|c|}{ Without RPG } & \multicolumn{3}{|c|}{ With RPG } \\
\hline & $\mathrm{V}$ & $\mathrm{L}$ & $\delta$ & $\mathrm{V}$ & $\mathrm{L}$ & $\delta$ \\
\hline 1 & 1.000 & - & 0.0 & 1.000 & - & 0.0 \\
\hline 2 & 1.000 & - & -8.5 & 1.000 & - & -0.5 \\
\hline 3 & 0.955 & 0.064 & -2.5 & 0.957 & 0.063 & -2.2 \\
\hline 4 & 0.958 & 0.064 & -10.4 & 0.958 & 0.063 & -2.7 \\
\hline 5 & 0.585 & 0.984 & -32.1 & 0.595 & 0.955 & -27.7 \\
\hline \multicolumn{7}{|c|}{ Case 2} \\
\hline 1 & 1.000 & 0.000 & 0.0 & 1.000 & 0.000 & 0.0 \\
\hline 2 & 1.000 & 0.000 & 41.1 & 1.000 & 0.000 & -3.0 \\
\hline 3 & 0.920 & 0.110 & -2.6 & 0.945 & 0.088 & -3.5 \\
\hline 4 & 0.959 & 0.041 & 38.5 & 0.983 & 0.032 & -4.2 \\
\hline 5 & 0.572 & 0.922 & -16.1 & 0.716 & 0.604 & -21.6 \\
\hline
\end{tabular}

Table 4

Internal Angle of Generators

\begin{tabular}{ccccc}
\hline Case 1 & \multicolumn{2}{c}{ Without RPG } & \multicolumn{2}{c}{ With RPG } \\
\cline { 2 - 5 } & G1 & G2 & G1 & G2 \\
\hline P (MW) & 217 & 170 & 194 & 190 \\
Q (Mvar) & 222 & 208 & 209 & 208 \\
$\delta$ (deg.) & 0 & -8.5 & 0 & -0.5 \\
E (pu) & 1.190 & 1.174 & 1.177 & 1.176 \\
$\delta_{\text {int }}$ (deg.) & 8.38 & -1.85 & 7.58 & 6.93 \\
\hline Case 2 & & & & \\
\hline P (MW) & 229 & 190 & 305 & 105 \\
Q (Mvar) & 397 & 208 & 268 & 81 \\
$\delta$ (deg) & 0 & 41 & 0 & -3.0 \\
E (pu) & 1.331 & 1.174 & 1.239 & 1.068 \\
$\delta_{\text {int }}$ (deg.) & 7.92 & 50.12 & 11.37 & 1.51 \\
\hline
\end{tabular}

From the Tables 2, 3 and 4 it can be seen that the percentage power loss, power loss in MW and the angle separation between the generators is less when the load sharing is according to the relative proportions of generation and they are more if the load sharing is not according to the relative proportions of generation. It means that the system angular stability is also improved.

\section{Relative Proportions of Generation (RPG) for System with Multiple Generators and Loads}

A sample six-bus system (system-2) shown in Fig.2 is considered.

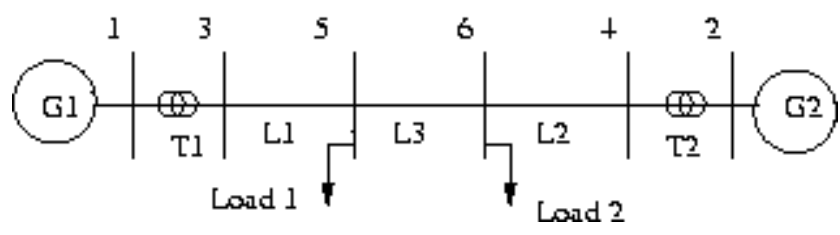

Fig. 2 Sample Radial System -2

\subsection{Case 1: Equal amount of Loads}

In this case it is assumed that the lines L1, L2 and L3 are of 200,300 and $100 \mathrm{kms}$ length respectively and each of $400 \mathrm{kV}$ line. The generators considered are two units of $250 \mathrm{MVA}$ with step up transformers of 250 MVA each at both buses 1 and 2. The $400 \mathrm{kV}$ line parameters in p.u. Per $100 \mathrm{kms}$ are $\mathrm{r}=0.0166, \mathrm{x}=0.0206$ and $\mathrm{b} / 2=0.2692$. The generator $X_{d}$ is considered 0.2 p.u. on its own base. The $\left[\boldsymbol{F}_{\boldsymbol{L} \boldsymbol{G}}\right]$ matrix corresponding to the load/generator bus for the network is given by

$$
\left[\boldsymbol{F}_{L G}\right]=\left[\begin{array}{ll}
.8999-0.0040 i & .1343+0.0021 i \\
.1343+0.0021 i & .8997-0.0040 i \\
.6717-0.0043 i & .4106-0.0017 i \\
.5464-0.0035 i & .5419-0.0030 i
\end{array}\right]
$$

The relative proportions of generation (RPG) to meet each load demand for the given network are shown in Table 5. The system grid total for maximum power transfer is shown in Table 6.

Table 5

Relative Proportions of Generation

\begin{tabular}{ccc}
\hline Load Bus & \multicolumn{2}{c}{ Generators } \\
\cline { 2 - 3 } No. & G1 & G2 \\
\hline 3 & .8999 & .1343 \\
4 & .1343 & .8997 \\
5 & .6717 & .4106 \\
6 & .5464 & .5419 \\
\hline
\end{tabular}

Table 6

System Grid Totals for Case 1

\begin{tabular}{|c|c|c|c|}
\hline & & Without RPG & With RPG \\
\hline \multirow{2}{*}{$\begin{array}{c}\text { Maximum } \\
\text { Load (MW) }\end{array}$} & Load 1 & 493 & 493 \\
\hline & Load 2 & 493 & 493 \\
\hline \multicolumn{2}{|c|}{ \%Power Loss } & 3.45 & 3.01 \\
\hline \multicolumn{2}{|c|}{ Power Loss (MW) } & 62.97 & 61.60 \\
\hline \multirow{2}{*}{$\begin{array}{l}\text { Generation } \\
\text { (MW) }\end{array}$} & G1 & 560 & 581 \\
\hline & G2 & 493 & 470 \\
\hline
\end{tabular}

Table 7

System Profiles for Case 1

\begin{tabular}{ccccccc}
\hline Bus & \multicolumn{3}{c}{ Without RPG } & \multicolumn{3}{c}{ With RPG } \\
\cline { 2 - 7 } No. & $\mathrm{V}$ & $\mathrm{L}$ & $\delta$ & $\mathrm{V}$ & $\mathrm{L}$ & $\delta$ \\
\hline 1 & 1.000 & - & 0.0 & 1.000 & - & 0.0 \\
2 & 1.000 & - & 5.3 & 1.000 & - & 1.5 \\
3 & 0.877 & 0.228 & -6.9 & 0.877 & 0.226 & -7.1 \\
4 & 0.903 & 0.173 & -0.6 & 0.907 & 0.171 & -4.1 \\
5 & 0.653 & 0.929 & -28.0 & 0.657 & 0.917 & -29.1 \\
6 & 0.639 & 0.990 & -28.8 & 0.647 & 0.970 & -30.4 \\
\hline
\end{tabular}


From the Tables 5, 6 and 7 it can be seen that the percentage power loss, power loss in MW and the angle separation between the generators is less when the load sharing is according to the relative proportions of generation.

\subsection{Case 2: Unequal amount of Loads}

In this case it is assumed that the loads at buses 5 and 6 are unequal in magnitude. The system grid totals for maximum power transfer are shown in Table 8.

Table 8

System Grid Totals for Case 2

\begin{tabular}{|c|c|c|c|}
\hline & & Without RPG & With RPG \\
\hline \multirow{2}{*}{$\begin{array}{c}\text { Maximum } \\
\text { Load (MW) }\end{array}$} & Load 1 & 593 & 593 \\
\hline & Load 2 & 393 & 393 \\
\hline \multicolumn{2}{|c|}{ \%Power Loss } & 3.57 & 2.73 \\
\hline \multicolumn{2}{|c|}{ Power Loss (MW) } & 64.33 & 60.85 \\
\hline \multirow{2}{*}{$\begin{array}{c}\text { Generation } \\
\text { (MW) }\end{array}$} & G1 & 661 & 594 \\
\hline & G2 & 393 & 456 \\
\hline
\end{tabular}

Table 9

System Profiles for Case 2

\begin{tabular}{ccccccc}
\hline Bus & \multicolumn{3}{c}{ Without RPG } & \multicolumn{3}{c}{ With RPG } \\
\cline { 2 - 7 } No. & $\mathrm{V}$ & $\mathrm{L}$ & $\delta$ & $\mathrm{V}$ & $\mathrm{L}$ & $\delta$ \\
\hline 1 & 1.000 & - & 0.0 & 1.000 & - & 0.0 \\
2 & 1.000 & - & -9.8 & 1.000 & - & 1.2 \\
3 & 0.861 & 0.240 & -8.3 & 0.874 & 0.231 & -7.3 \\
4 & 0.915 & 0.167 & -14.4 & 0.912 & 0.164 & -4.2 \\
5 & 0.632 & 0.988 & -34.8 & 0.652 & 0.940 & -30.0 \\
6 & 0.651 & 0.948 & -35.6 & 0.660 & 0.920 & -29.1 \\
\hline
\end{tabular}

Table 9 shows the variation of voltage profile (V), voltage stability index (L) and bus angles $(\delta)$ for the sample radial system 2 . From the Tables 7, 8 and 9 it can be seen that the percentage power loss, power loss in MW and the angle separation between the generators is less when the load sharing is according to the relative proportions of generation and they are more if the load sharing is not according to the relative proportions of generation.

\section{24- Bus Equivalent EHV Power System}

The proposed approach has been tested on large interconnected networks. The results for a practical system of 24-bus equivalent EHV power system network shown in Fig.3 are presented in this section. The system has 4 generator buses and 20 other buses. The load is represented at $220 \mathrm{kV}$ side of $400 \mathrm{kV} / 220 \mathrm{kV}$ nodes at 8 number of buses.

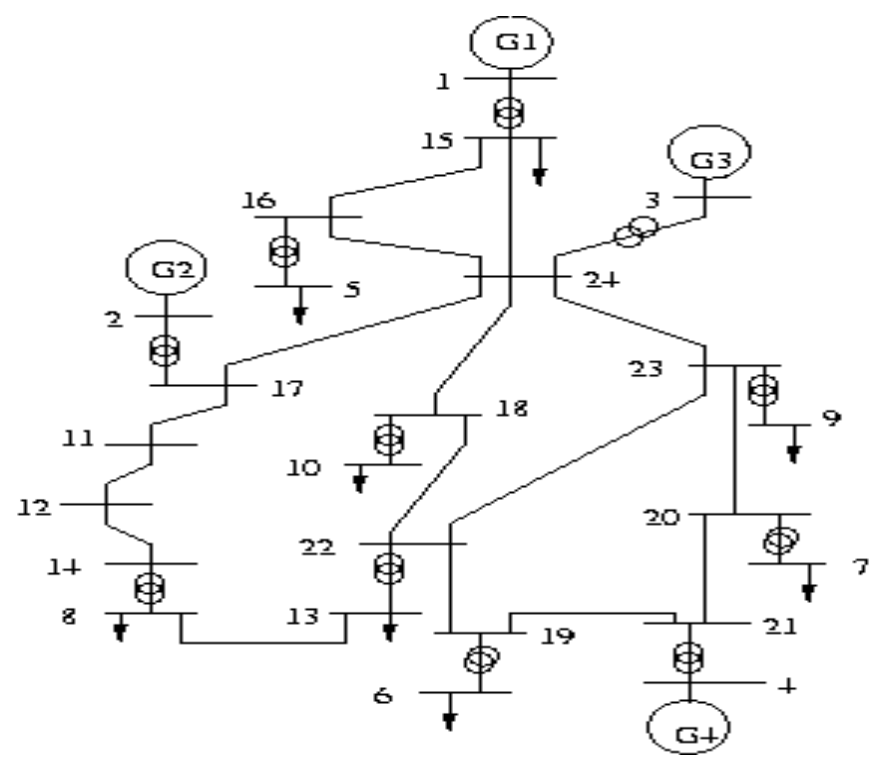

Fig 3. 24-Bus Equivalent Practical Power System

\subsection{Case1: base case condition}

The Relative Proportions of Generation (RPG) for the 24bus system, which are obtained from the $\boldsymbol{F}_{L G}$ matrix, are shown in the Table 10.

Table 10.

Relative Proportions of Generation

\begin{tabular}{ccccc}
\hline Load & \multicolumn{4}{c}{ RPG values of Loads from Generators } \\
\cline { 2 - 5 } Bus No. & G1 & G2 & G3 & G4 \\
\hline 5 & .5534 & .0789 & .3335 & .0855 \\
6 & .1342 & .0834 & .1761 & .6735 \\
7 & .1712 & .0788 & .2247 & .5954 \\
8 & .2164 & .2237 & .2840 & .3997 \\
9 & .2767 & .1155 & .3632 & .3481 \\
10 & .2943 & .1321 & .3863 & .2903 \\
13 & .2191 & .1818 & .2876 & .4282 \\
15 & .8413 & .0286 & .1209 & .0310 \\
\hline
\end{tabular}

Table 11

Generation Scheduling With RPG Values

\begin{tabular}{cccccc}
\hline $\begin{array}{c}\text { Load } \\
\text { Bus No. }\end{array}$ & \multicolumn{4}{c}{ Generators Load Sharing (MW) } & $\begin{array}{c}\text { Load at } \\
\text { the bus } \\
\text { (MW) }\end{array}$ \\
\cline { 2 - 5 } & G1 & G2 & G3 & G4 & (MW \\
\hline 5 & 237.97 & 33.91 & 143.39 & 36.75 & 430 \\
6 & 37.58 & 23.34 & 49.32 & 188.58 & 280 \\
7 & 54.78 & 25.22 & 71.89 & 190.53 & 320 \\
8 & 38.95 & 40.27 & 51.12 & 71.95 & 180 \\
9 & 33.21 & 13.86 & 43.58 & 41.77 & 120 \\
10 & 17.66 & 7.92 & 23.18 & 17.42 & 60 \\
13 & 98.60 & 81.80 & 129.41 & 192.69 & 450 \\
15 & 656.18 & 22.29 & 94.27 & 24.16 & 780 \\
\hline Gen. & 1175 & 248.6 & 606 & 764 & \\
Sum & & & & & \\
\hline
\end{tabular}


The system generation scheduling is obtained by the corresponding load sharing by the generators according to the Relative Proportions of Generation (RPG) values for a peak load condition of $2620 \mathrm{MW}, 980 \mathrm{MVAR}$ and is shown in Table 11. Power flow results are obtained for the peak load condition with and without Relative Proportions of Generation (RPG) values and results are summarized in Table 12 and 13.

Table 12

System Grid Totals

\begin{tabular}{ccccccc}
\hline & & & & \multicolumn{4}{c}{ Generation (in MW) } \\
\cline { 5 - 7 } & Power & Power & Loss \\
\cline { 5 - 7 } & loss & $(\mathrm{MW})$ & G1 & G2 & G3 & G4 \\
\hline $\begin{array}{c}\text { Without } \\
\text { RPG }\end{array}$ & 2.42 & 64.94 & 1655 & 160 & 350 & 520 \\
With RPG & 1.89 & 50.47 & 1052 & 249 & 606 & 764 \\
\hline
\end{tabular}

Table 13

Internal Angle of Generators

\begin{tabular}{cccccc}
\hline With & Gen. & $\mathrm{P}$ & $\begin{array}{c}\mathrm{Q} \\
\text { Mvar }\end{array}$ & $\begin{array}{c}\mathrm{E} \\
\mathrm{Pu}\end{array}$ & $\begin{array}{c}\delta_{\text {int. }} \\
\text { (deg.) }\end{array}$ \\
\cline { 2 - 6 } No. & $\mathrm{MW}$ & 1051 & 373 & 1.547 & 32.93 \\
& 2 & 249 & 21 & 1.036 & 13.48 \\
& 3 & 606 & 148 & 1.219 & 25.24 \\
& 4 & 764 & 341 & 1.411 & 29.57 \\
\hline Without & 1 & 1655 & 518 & 1.937 & 43.12 \\
RPG & 2 & 160 & 36 & 1.036 & -5.50 \\
& 3 & 350 & 193 & 1.188 & 2.73 \\
& 4 & 520 & 300 & 1.308 & -.459 \\
\hline
\end{tabular}

From the above Tables 12 and 13 it can be seen that the percentage power loss and the angle separation between the generators are minimum when the load sharing is according to the relative proportions of generation and they are more if the load sharing is not according to the relative proportions of generation. Also the improvement of Voltage Stability Indices for the 24- bus system is shown in Table 14 .

The voltage stability indices at all the 20 load buses and the maximum value of voltage stability index is reduced from 0.542 to 0.529 at bus number 13 when the load sharing / generation scheduling is according to the relative proportions of generation as given in the above Table 14 . The improvement of voltage profiles and bus angles for the 24-bus system are shown in Fig 4 and 5 respectively.

From the Figs. 4 and 5 we can see that the minimum voltage profile has been increased from 0.847 to 0.858 and the maximum bus angle is decreased from $-35^{\circ}$ to $-20^{\circ}$ when the load sharing is according to the relative proportions of generation giving reduction of bus angle by $15^{\circ}$. It means the system has more angle stability when the load sharing /generation scheduling is according to the relative proportions of generation.

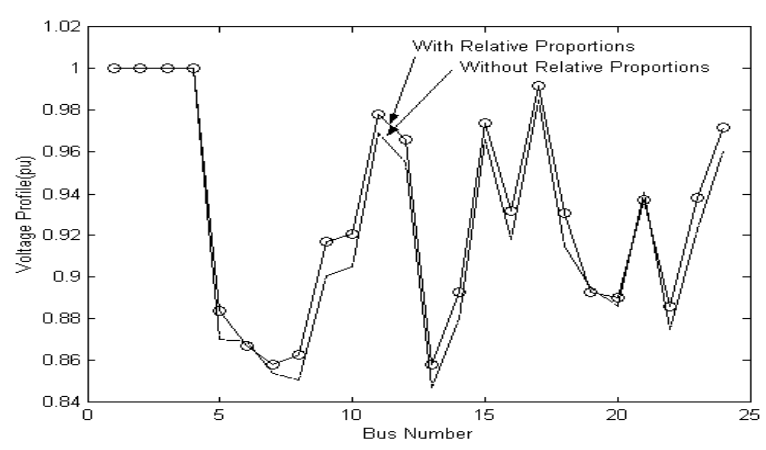

Fig. 4. Voltage profile Improvement

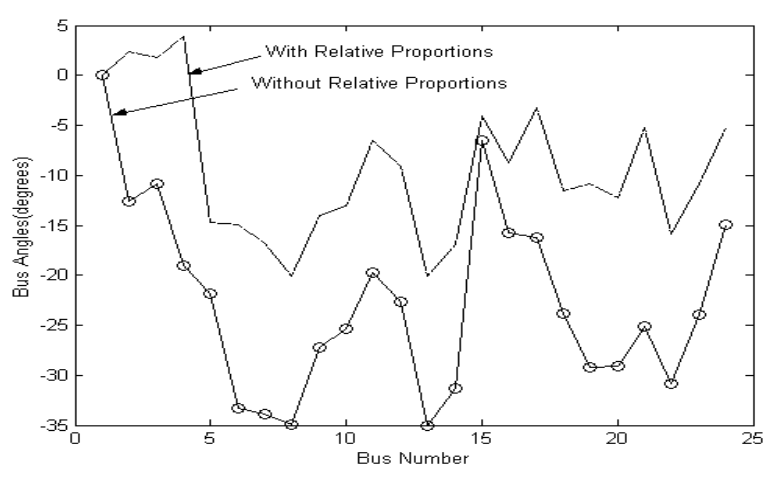

Fig 5. Bus angle Improvement

Table 14

Voltage Stability Indices

\begin{tabular}{ccc}
\hline Load Bus No. & \multicolumn{2}{c}{ Voltage Stability Indices (L) } \\
\cline { 2 - 3 } & Without RPG & With RPG \\
\hline 5 & 0.360 & 0.350 \\
6 & 0.412 & 0.411 \\
7 & 0.453 & 0.449 \\
8 & 0.542 & 0.529 \\
9 & 0.371 & 0.362 \\
10 & 0.350 & 0.341 \\
11 & 0.201 & 0.198 \\
12 & 0.267 & 0.262 \\
13 & 0.540 & 0.528 \\
14 & 0.464 & 0.454 \\
15 & 0.093 & 0.093 \\
16 & 0.226 & 0.221 \\
17 & 0.122 & 0.120 \\
18 & 0.316 & 0.309 \\
19 & 0.325 & 0.324 \\
20 & 0.348 & 0.345 \\
21 & 0.198 & 0.197 \\
22 & 0.437 & 0.429 \\
23 & 0.302 & 0.296 \\
24 & 0.150 & 0.148 \\
20 & 0.348 & 0.345 \\
21 & 0.198 & 0.197 \\
22 & 0.437 & 0.429 \\
23 & 0.302 & 0.296 \\
24 & 0.150 & 0.148 \\
\hline
\end{tabular}




\subsection{Case 2: line 22-23 outage contingency}

The Relative Proportions of Generation (RPG) for the 24bus system under contingency, which are obtained from the

$\boldsymbol{F}_{L G}$ matrix, are shown in the Table 15. The system generation scheduling is obtained by the corresponding load sharing by the generators according to the Relative Proportions of Generation (RPG) values for a peak load condition of $2620 \mathrm{MW}, 980$ MVAR and is shown in Table 16.

Table 15

Relative Proportions of Generation

\begin{tabular}{ccccc}
\hline Load & \multicolumn{4}{c}{ RPG values of Loads from Generators } \\
\cline { 2 - 5 } Bus No. & G1 & G2 & G3 & G4 \\
\hline 5 & .5546 & .0766 & .3350 & .0785 \\
6 & .1140 & .0908 & .1496 & .6966 \\
7 & .1761 & .0715 & .2311 & .5731 \\
8 & .1766 & .2401 & .2318 & .4506 \\
9 & .2980 & .0965 & .3911 & .2896 \\
10 & .2719 & .1402 & .3568 & .3155 \\
13 & .1759 & .1997 & .2309 & .4838 \\
15 & .8417 & .0278 & .1214 & .0284 \\
\hline
\end{tabular}

Table 16

Generation Scheduling With RPG Values

\begin{tabular}{cccccc}
\hline $\begin{array}{c}\text { Load } \\
\text { Bus No. }\end{array}$ & \multicolumn{4}{c}{ Generators Load Sharing (MW) } & $\begin{array}{c}\text { Load at } \\
\text { the bus } \\
\end{array}$ \\
\cline { 2 - 5 } (MW)
\end{tabular}

Power flow results are obtained for the peak load condition with and without Relative Proportions of Generation (RPG) values and results are summarized in Tables 17 and 18.

Table 17

System Grid Totals

\begin{tabular}{cccccccc}
\hline & & & & \multicolumn{4}{c}{ Generation (in MW) } \\
\cline { 5 - 7 } & $\begin{array}{c}\text { Power } \\
\text { loss }\end{array}$ & $\begin{array}{c}\text { Power } \\
\text { Loss }\end{array}$ & G1 & G2 & G3 & G4 \\
\hline $\begin{array}{c}\text { Without } \\
\text { RPG }\end{array}$ & 2.14 & 89.90 & 1679 & 160 & 350 & 520 \\
With RPG & 1.56 & 72.24 & 1091 & 256 & 569 & 787 \\
\hline
\end{tabular}

Table 18

Internal Angle of Generators

\begin{tabular}{|c|c|c|c|c|c|}
\hline \multirow[t]{5}{*}{ RPG } & $\begin{array}{c}\text { Gen. } \\
\text { No. }\end{array}$ & $\begin{array}{c}\mathrm{P} \\
\mathrm{MW}\end{array}$ & $\begin{array}{c}\text { Q } \\
\text { Mvar }\end{array}$ & $\begin{array}{c}\mathrm{E} \\
\mathrm{Pu} \\
\end{array}$ & $\begin{array}{c}\delta_{\text {int. }} \\
\text { (deg.) }\end{array}$ \\
\hline & 1 & 1091 & 478 & 1.117 & 11.26 \\
\hline & 2 & 256 & 125 & 1.119 & 11.85 \\
\hline & 3 & 569 & 276 & 1.084 & 8.95 \\
\hline & 4 & 787 & 489 & 1.150 & 14.23 \\
\hline Without & 1 & 1679 & 665 & 1.080 & 8.95 \\
\hline \multirow[t]{3}{*}{ RPG } & 2 & 160 & 155 & 1.131 & -8.81 \\
\hline & 3 & 350 & 361 & 1.153 & -4.83 \\
\hline & 4 & 520 & 383 & 1.172 & -14.38 \\
\hline
\end{tabular}

From the above Tables 17 and 18 it can be seen that the percentage power loss and the angle separation between the generators are minimum when the load sharing is according to the relative proportions of generation and they are more if the load sharing is not according to the relative proportions of generation. Also the improvement of Voltage Stability Indices for the 24- bus system is shown in Table 19.

The voltage stability indices at all the 20 load buses and the maximum value of voltage stability index is reduced from 0.925 to 0.915 at bus number 13 when the load sharing / generation scheduling is according to the relative proportions of generation as given in the above Table 19 . The improvement of voltage profiles and bus angles for the 24-bus system are shown in Fig 6 and 7 respectively.

Table 19

Voltage Stability Indices

\begin{tabular}{ccc}
\hline Load Bus No. & \multicolumn{2}{c}{ Voltage Stability Indices (L) } \\
\cline { 2 - 3 } & Without RPG & With RPG \\
\hline 5 & 0.378 & 0.366 \\
6 & 0.612 & 0.612 \\
7 & 0.527 & 0.514 \\
8 & 0.912 & 0.900 \\
9 & 0.352 & 0.338 \\
10 & 0.514 & 0.493 \\
11 & 0.280 & 0.273 \\
12 & 0.395 & 0.384 \\
13 & 0.925 & 0.915 \\
14 & 0.764 & 0.747 \\
15 & 0.096 & 0.095 \\
16 & 0.237 & 0.230 \\
17 & 0.153 & 0.150 \\
18 & 0.468 & 0.450 \\
19 & 0.488 & 0.486 \\
20 & 0.401 & 0.390 \\
21 & 0.267 & 0.264 \\
22 & 0.760 & 0.750 \\
23 & 0.279 & 0.268 \\
24 & 0.160 & 0.156 \\
\hline
\end{tabular}




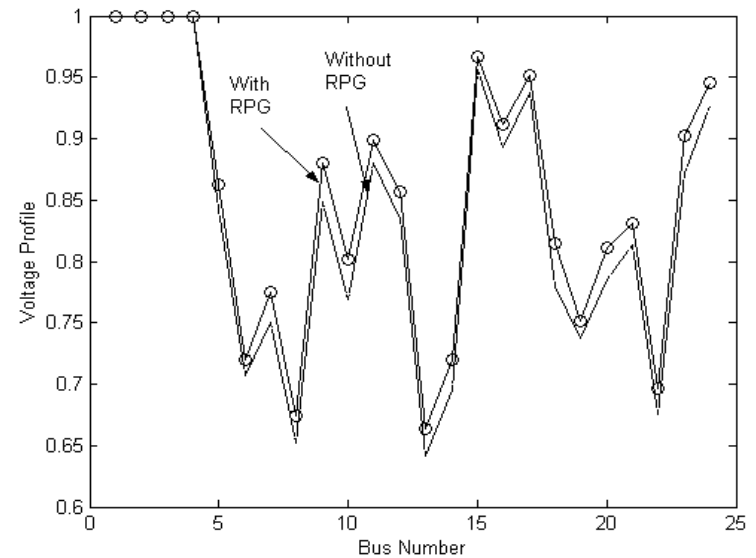

Fig. 6. Voltage profile Improvement

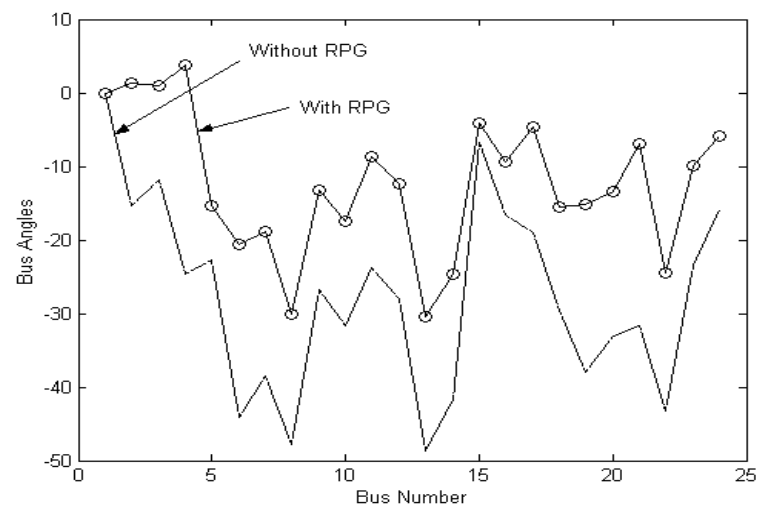

Fig. 7. Bus angle Improvement

From the Figs. 6 and 7 we can see that the minimum voltage profile has been increased from 0.642 to 0.664 and the maximum bus angle is decreased from $-47.8^{0}$ to $-30.1^{0}$ when the load sharing is according to the relative proportions of generation giving reduction of bus angle by $17.7^{0}$. It means the system has more angle stability when the load sharing/generation scheduling is according to the relative proportions of generation

\section{Conclusions}

In this paper a new concept, called relative proportion of generation (RPG), is used to load sharing /generation scheduling for improving angular stability in addition to improving voltage stability. The proposed approach gives a better way of improving stability margins using the existing generation facilities. It can also be used more effectively under contingency condition for optimal load sharing to improve stability margins. The results on the equivalent practical system illustrate the application of the approach for large power systems. The proposed method has been tested on typical sample systems and also a practical 24-bus power system and results are presented to illustrate efficiency of the proposed approach.

\section{References}

[1] G.T. Heydt, C.C. Liu, A.G. Phadke, V. Vittal, Solutions for the Crisis in Electric Power Supply, IEEE Computer Applications in Power, (2001) 22-30.

[2] P. Kessel, H. Glavitsch, Estimating the voltage Stability of a Power System, IEEE Transactions on Power Delivery,13(1986) 346-354.

[3] Bansilal, D. Thukaram, K. Parthasarathy, Optimal reactive power dispatch algorithm for voltage stability improvement", Electrical Power and Energy Systems 18 (7) (1996) 461-468.

[4] A.N. Udupa, D. Thukaram, K. Parthasarathy, An expert fuzzy control approach to voltage stability enhancement, Electrical Power and Energy Systems, 21(199) 279-287.

[5] D. Thukaram, K. Parthasarathy, H.P. Khincha, A.N. Udupa, Bansilal, Voltage Stability Improvement; Case Studies of Indian Power Networks, Electric Power Systems Research, 44(1998) $35-44$.

[6] D. Thukaram , Abrahaham Lomi, Selection of Static VAR Compensator Location and Size for System Voltage Stability Improvement, Electric Power Systems Research, 54(2000) 139150 . 